\title{
PRODUÇÃO E QUALIDADE DE ABÓBORA EM FUNÇÃO \\ DA IDADE DAS MUDAS E TIPO DE BANDEJA $\left({ }^{1}\right)$
}

\author{
MARIELE FERNANDA PIOVESAN $\left({ }^{2}\right)$; ANTONIO ISMAEL INÁCIO CARDOSO $\left({ }^{2 *}\right)$
}

\begin{abstract}
RESUMO
O objetivo do experimento foi estudar o efeito do tipo de bandeja e da idade das mudas na produção de abóbora, híbrido Atlas. Foram avaliados dois tipos de bandeja (72 e 128 células) e quatro idades das mudas (19, 24, 29 e 34 dias após a semeadura) no delineamento em blocos ao acaso, com seis repetições e cinco plantas por parcela. As características avaliadas foram a produção (número e massa) de frutos por planta e as dimensões dos frutos (comprimento total, do bojo, do pescoço, diâmetro do bojo e do pescoço). Apesar de não ter havido efeito estatístico sobre a produtividade, houve redução linear para a maioria das características do fruto (comprimento, diâmetro e massa) com o aumento da idade das mudas. Assim, observou-se que mudas mais velhas, com a parte aérea mais desenvolvida e as preferidas por alguns produtores por seu sistema radicular compacto e a maior facilidade para serem transplantadas, podem reduzir a qualidade de abóbora.
\end{abstract}

Palavras-chave: Cucurbita moschata, produção de mudas, propagação.

\section{ABSTRACT \\ SQUASH PRODUCTION AND QUALITY IN FUNCTION OF SEEDLING AGE AND CONTAINER TYPE}

The purpose of this research was to study the effect of tray type and seedling age in the production of squash, hybrid Atlas. Two tray types (72 and 128 cells) and four seedling ages (19, 24, 29 and 34 days after sowing) were evaluated in randomized blocks design, with six replication and five plants per plot. Fruit yield, average fruit weight and fruit dimensions (total length, neck and seed cavity length and diameter) were evaluated. Besides absence of significant statistical difference in fruit yield, for most of fruit characteristics (average weight, length and diameter) a linear reduction was observed in aging seedling. Therefore, older seedlings with more developed shoots, and which are preferred by some producers due to their compact radicular system and easiness to transplant, may present lower squash quality.

Key words: Cucurbita moschata, seedling production, propagation.

$\left.{ }^{1}\right)$ Recebido para publicação em 13 de setembro de 2007 e aceito em 16 de fevereiro de 2009.

$\left(^{2}\right)$ Departamento de Produção Vegetal, Faculdade de Ciências Agronômicas, Universidade Estadual Paulista, Caixa Postal 237, 18603-970 Botucatu (SP). E-mail: ismaeldh@fca.unesp.br ${ }^{*}$ ) Autor correspondente. 


\section{INTRODUÇÃO}

Têm sido lançadas no mercado sementes de híbridos de abóboras com preço superior ao das cultivares de polinização aberta. Devido ao maior custo, os produtores têm utilizado bandejas para produção de mudas. Nas bandejas há melhor aproveitamento das sementes, produzindo cada semente uma muda. Comparada à semeadura direta, com o uso dessa tecnologia ocorre diminuição nas falhas de pegamento, bem como aumento na uniformidade inicial das plantas (MINAMI, 1995).

Atualmente, utilizam-se, na produção de mudas, bandejas com células de vários tamanhos e para maximizar a produção de mudas no viveiro, utilizam-se células com o menor volume possível. Porém, a redução de volume pode prejudicar a qualidade da muda e, consequentemente, a produtividade e qualidade do produto. A restrição radicular, observada em pequenos volumes de célula, pode afetar o crescimento, a fotossíntese, o teor de clorofila nas folhas, a absorção de nutrientes e água, a respiração, o florescimento, bem como a produção (NeSmith e Duval, 1998). A maior massa de raízes em recipientes pequenos contribui para a redução do espaço poroso gerando maior competição por oxigênio. As mudas com sistema radicular restringido, quando transplantadas, são freqüentemente incapazes de compensar a evapotranspiração, mesmo se bem irrigadas após o transplante (Pereira e Martinez, 1999).

Modolo (1998), ao estudar diferentes volumes de células $\left(16,32\right.$ e $\left.72 \mathrm{~cm}^{3}\right)$ em quiabeiro, verificou maior produção nos maiores volumes de célula. Em melancia, HALL (1989) concluiu que a produtividade pode depender da cultivar, pois observou aumento em 'Charleston Gray', produzida em células com $40 \mathrm{~cm}^{3}$, em detrimento daquela semeada em células de $19 \mathrm{~cm}^{3}$. Porém, na cultivar Crimson Sweet, o volume das células não afetou a produção. Em contradição ao resultado anterior, VAVRINA et al. (1993) não observaram influência do tamanho da célula na produtividade da melancia 'Charleston Gray'. Já para o híbrido Star Brite, LiU e LATimer (1995) observaram aumento linear com o aumento do volume de células para o desenvolvimento das mudas, número de frutos por planta, número de frutos comerciais e produtividade.

Em pepino, BARros (1997) verificou que quanto maior o volume da célula da bandeja $\left(16,36\right.$ e $\left.72 \mathrm{~cm}^{3}\right)$, maior a massa fresca e seca da parte aérea, das raízes e área foliar das mudas. SEABRA JúNIOR et al. (2004) observaram maior produtividade com a utilização de bandejas com $121 \mathrm{~cm}^{3}$, comparado com $35 \mathrm{~cm}^{3}$. No melão, o volume da célula influenciou na precocidade da produção, porém não houve influência no número e massa de frutos (MAYNARD et al., 1996).

Outro fator importante que pode afetar a qualidade e a produtividade das plantas é a idade das mudas para o transplante. Se a muda for mantida por um período muito grande na bandeja, poderá ocorrer deficiência de nutrientes e redução da sua qualidade. O tempo em que as mudas permanecem com seu sistema radicular restringido deve ser o mínimo possível (Pereira e Martinez, 1999). Para as cucurbitáceas é recomendado que se transplante as mudas com três semanas de idade e duas folhas (BORNE, 1999), pois são plantas que possuem desenvolvimento rápido.

Não foi observada influência da idade na precocidade de produção em tomate (LESKOVAR et al., 1991), abobrinha (NeSMITH, 1993) e melancia (VAVRINA et al., 1993). Segundo Kemble et al. (1994), a idade ideal para o transplante de mudas de tomateiro está relacionada com o volume de célula em que esta foi produzida, verificando que geralmente mudas com cinco semanas produziram antes do que mudas com quatro semanas, exceto quando as mudas eram produzidas em volume de células menores. A idade da muda não afetou a produção na cultura de melancia (VAVRina et al., 1993). Já em pepino, SEABrA JúNIOR et al. (2004) observaram redução na produtividade com a utilização de mudas velhas.

Segundo Belfort e Gomes (2000), o insucesso de muitos empreendedores tem sido atribuído à nãoobservação do momento adequado para o transplante. A idade em que as mudas vêm sendo transplantadas pode prejudicar sua qualidade. O volume de célula utilizado pode não ser compatível com o tempo de permanência da muda na bandeja, e restringir o desenvolvimento radicular.

Para produtores de mudas, ocorre a tendência de se comercializar mudas mais novas, para reduzir o tempo delas no viveiro de produção. Os produtores que vão cultivar estas mudas preferem as mais desenvolvidas. Provavelmente, esta preferência está relacionada com a facilidade de transplante, pois seu sistema radicular compacto não se quebra no momento da retirada das bandejas (SEABRA JÚNIOR et al., 2004).

Assim, o objetivo desta pesquisa foi estudar o efeito do tipo de bandeja e da idade das mudas na produção e qualidade de abóbora.

\section{MATERIAL E MÉTODOS}

As mudas foram produzidas em ambiente protegido, em uma estrutura tipo arco, com $7 \times 20 \mathrm{~m}$ 
e pé direito de $2,5 \mathrm{~m}$, coberta com filme de polietileno transparente de $150 \mu \mathrm{m}$ de espessura e lateralmente com tela antiafídeos.

Para a semeadura foram utilizadas bandejas de poliestireno expandido com 72 e 128 células, correspondentes a um volume por célula de $121,2 \mathrm{~cm}^{3}$ e $34,6 \mathrm{~cm}^{3}$ respectivamente. Essas foram preenchidas com substrato comercial (Plantmax $\mathrm{HT}^{\circledR}$ ), utilizandose uma semente por célula do híbrido $F_{1}$ Atlas da empresa Sakata Seed Sudamerica, do tipo Butternut americano, de rama curta.

O delineamento experimental utilizado foi em blocos ao acaso, com seis repetições em esquema fatorial cujo primeiro fator foi dois tipos de bandeja (72 e 128 células) e o segundo fator, a idade de mudas $(19,24,29$ e 34 dias após a semeadura - DAS). Foram avaliadas cinco plantas por parcela. As semeaduras foram realizadas a cada cinco dias $(10 / 1,15 / 1,20 /$ 1 e $25 / 1 / 07)$ para ser feito o transplante das plantas de todos os tratamentos no mesmo dia $(13 / 2 / 2007)$ em canteiros com $1,0 \mathrm{~m}$ de largura. $\mathrm{O}$ espaçamento utilizado foi de $2,0 \times 1,5 \mathrm{~m}$.

O solo da área experimental é Latossolo Vermelho Distrófico Típico (EMbrapa, 1999). Os resultados constantes da análise química do solo na camada de $0-20 \mathrm{~cm}$ de profundidade antes da instalação do experimento foram: $\mathrm{pH}\left(\mathrm{CaCl}_{2}\right)=6,0 ; \mathrm{P}_{\text {resina }}=69 \mathrm{mg}$ $\mathrm{dm}^{-3} ;$ matéria orgânica $=9 \mathrm{~g} \mathrm{dm}^{3} ; \mathrm{V} \%=75 ; \mathrm{H}+\mathrm{Al}=13$ $\mathrm{mmol}_{\mathrm{C}} \mathrm{dm}^{-3} ; \mathrm{K}=0,9 \mathrm{mmol}_{\mathrm{c}} \mathrm{dm}^{-3} ; \mathrm{Ca}=28 \mathrm{mmol}_{\mathrm{C}} \mathrm{dm}^{-3}$; $\mathrm{Mg}=9 \mathrm{mmol}_{\mathrm{c}} \mathrm{dm}^{-3} ; \mathrm{SB}=38 \mathrm{mmol}_{\mathrm{c}} \mathrm{dm}^{-3}$ e CTC $=51$ $\mathrm{mmol}_{\mathrm{c}} \mathrm{dm}^{-3}$. A adubação de plantio foi feita com $2 \mathrm{~L}$ de esterco de galinha e $200 \mathrm{~g}$ da fórmula 4-20-20 por cova, conforme recomendação de adubação para o Estado de São Paulo (RAIJ et al., 1996). Semanalmente, fez-se adubação de cobertura com $5 \mathrm{~g}$ de sulfato de amônia por cova. A irrigação utilizada foi feita por aspersão e o controle fitossanitário conforme a necessidade da cultura.

No dia do transplante $(13 / 2 / 2007)$, foram separadas amostras de 10 plantas de cada bandeja para avaliação do número de folhas, área foliar, altura, massa fresca e seca da parte aérea e massa fresca e seca da raiz. Como não havia repetições de bandejas, não foi possível realizar análise estatística de comparação entre as mudas. Esta avaliação foi feita apenas para caracterizar as mudas.

A colheita dos frutos foi realizada dia 24 de abril, colhendo-se todos os frutos maduros. Realizaram-se avaliações do número de frutos por planta, da massa, do comprimento total, do comprimento do pescoço e do bojo, do diâmetro do pescoço e do bojo dos frutos. Todos os frutos colhidos foram avaliados, obtendo-se a média de produção por planta e a massa, comprimentos e diâmetros por fruto.
Os dados obtidos para as características avaliadas foram analisados estatisticamente através da análise de variância com teste F. Quando houve significância para o fator idade, foi feita análise de regressão, definindo o melhor ajuste, segundo combinação de significância e maior coeficiente de determinação. Quando houve efeito do fator bandeja, foi aplicado teste de Tukey (5\%) para comparação de médias.

\section{RESULTADOS E DISCUSSÃO}

Sabe-se que em maiores volumes de células de bandejas observam-se maior tamanho, altura e número de folhas nas mudas, conforme observado neste trabalho (Tabela 1) e também relatado para pepino (BARROS, 1997; SEABRA JÚNIOR et al., 2004), alface (SILVA et al., 2000), berinjela (BARNABÉ e GIORGETTI, 1994) e beterraba (ECHER et al., 2000). Entretanto, não houve comprovação estatística desses resultados neste experimento.

Para as características número e massa de frutos por planta, a interação entre os fatores idade das mudas no transplante e tipo de bandeja não foi significativa, assim como os fatores idade e bandeja, isoladamente. Em média, foram colhidos 3,6 frutos e $6241 \mathrm{~g}$ por planta. Ressalta-se que houve dificuldade no transplante das mudas produzidas nas bandejas de 72 células aos 19 DAS, devido ao torrão não estar bem formado e se desfazer na retirada da muda da bandeja. A ausência de efeito na produtividade nas plantas produzidas em diferentes bandejas difere dos resultados relatados por SEABRA Júnior et al. (2004), em pepino; NeSmith (1993) em abobrinha; LeSKOVAR et al. (1991) em tomate; VAVRINA et al. (1993) e Liu e LATIMER (1995) em melancia.

$\mathrm{Na}$ bandeja de 72 células, observaram-se frutos com maior comprimento do bojo que na bandeja com 128 células apenas para mudas com 24 dias. Não se observou, porém, diferença entre as idades em ambas as bandejas (Tabela 2).

Para as características comprimento total e do pescoço dos frutos apenas o fator idade foi significativo. Observou-se uma redução linear para ambos com o aumento da idade das mudas (Figura 1). Em média, obteve-se redução de 0,12 e 0,10 cm, respectivamente, no comprimento total e do pescoço para cada dia de atraso no transplante das mudas.

Também houve efeito estatístico para o diâmetro do bojo e do pescoço dos frutos para o fator idade das mudas, havendo redução linear com o aumento da idade das mudas (Figura 2). Obteve-se, em média, uma redução de $0,06 \mathrm{~cm}$ nos diâmetros tanto do pescoço como do bojo para cada dia de atraso no transplante das mudas. 
Tabela 1. Número de folhas (NF), altura das mudas (AM), área foliar (AF), massa fresca (MFPA) e seca (MSPA) da parte aérea, massa fresca (MFR) e seca (MSR) das raízes das mudas de abóboras, em função do tipo de bandeja (128 e 72 células) e da idade para o transplante (34, 29, 24 e 19 DAS - dias após a semeadura)

\begin{tabular}{lcccccccc}
\hline Idade das mudas & Bandeja & NF & AM & AF & MFPA & MSPA & MFR & MSR \\
\hline dias & & unid. & $\mathrm{cm}$ & $\mathrm{cm}^{2}$ & & & \\
\cline { 5 - 8 } & 72 & 5,50 & 15,37 & 232,63 & 151,09 & 20,00 & 22,03 & 2,10 \\
34 & 128 & 3,70 & 13,16 & 111,80 & 75,99 & 8,10 & 7,26 & 0,70 \\
& 72 & 5,30 & 14,15 & 271,48 & 160,49 & 18,50 & 15,80 & 1,90 \\
29 & 128 & 3,70 & 14,05 & 95,56 & 65,21 & 6,50 & 9,07 & 0,70 \\
& 72 & 4,20 & 15,83 & 208,04 & 135,94 & 10,70 & 13,34 & 1,00 \\
24 & 128 & 3,10 & 11,78 & 103,01 & 60,43 & 5,70 & 4,24 & 0,50 \\
& 72 & 3,50 & 11,29 & 295,42 & 124,00 & 9,30 & 14,90 & 1,00 \\
19 & 128 & 3,00 & 6,00 & 122,68 & 61,39 & 5,10 & 5,44 & 0,50 \\
\hline
\end{tabular}

Tabela 2. Comprimento do bojo dos frutos de abóbora em função das diferentes idades das mudas e tipos de bandejas

\begin{tabular}{|c|c|c|c|c|}
\hline \multirow{2}{*}{ Bandeja } & \multicolumn{4}{|c|}{ Idade das mudas (DAS) } \\
\hline & 19 & 24 & 29 & 34 \\
\hline 72 células & 10,15 a $\mathrm{A}$ & 10,09 a $\mathrm{A}$ & 9,49 a $\mathrm{A}$ & 9,37 a $A$ \\
\hline 128 células & 9,82 a $A$ & $9,29 \mathrm{~b} \mathrm{~A}$ & 9,75 a $\mathrm{A}$ & 9,96 a $A$ \\
\hline
\end{tabular}

Médias seguidas da mesma letra, minúsculas nas colunas e maiúsculas nas linhas, não diferem estatisticamente pelo teste de Tukey a $5 \%$ de probabilidade.

DAS - dias após a semeadura

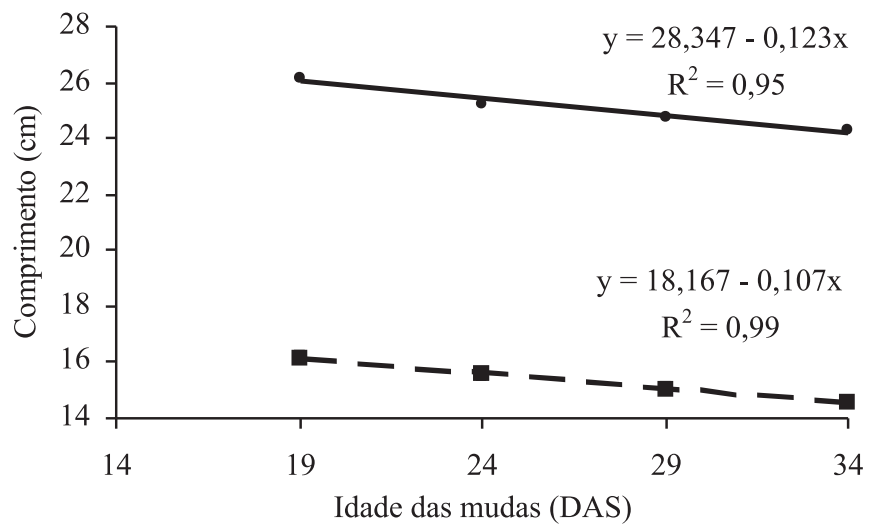

Figura 1. Comprimento total (linha contínua) e do pescoço (linha tracejada) dos frutos de abóbora em função da idade das mudas (DAS - dias após a semeadura).

Para a massa média dos frutos, observou-se redução linear com o aumento da idade das mudas (Figura 3), obtendo-se em média uma redução de 16,8 g para cada dia de atraso no transplante das mudas.

Para a maioria das características do fruto (comprimento, diâmetro e massa média) observou-se redução no valor com o aumento da idade das mudas. Nas mudas que permaneceram mais tempo nas

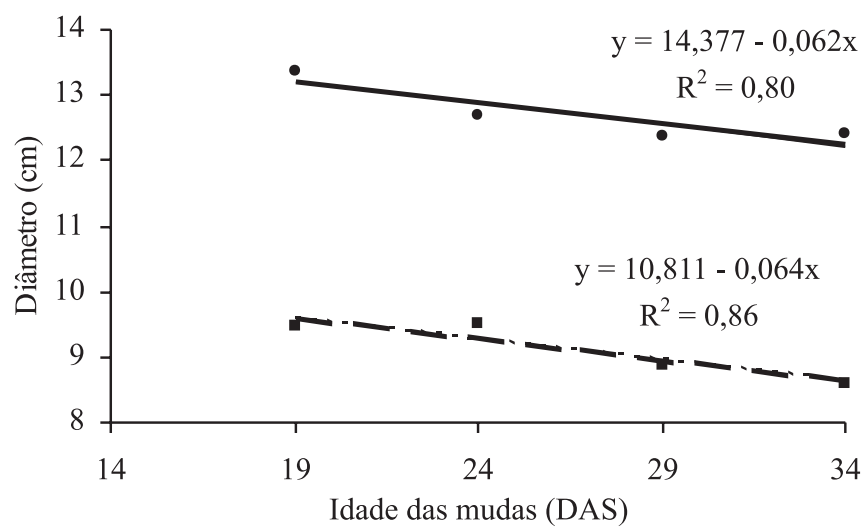

Figura 2. Diâmetro do bojo (linha contínua) e do pescoço (linha tracejada) dos frutos de abóbora em função da idade das mudas (DAS - dias após a semeadura.

bandejas foi percebido enegrecimento das raízes, que está associado à sua morte; assim essas plantas tiveram que emitir novas raízes para regenerarem o sistema radicular, afetando o desenvolvimento da planta após o transplante. Segundo NeSMith e Duval (1998) e Pereira e Martinez (1999), o tempo em que as mudas permanecem com seu sistema radicular restringido deve ser o mínimo possível, pois com essa 
restrição reduz-se o fornecimento de nutrientes para a parte aérea. Provavelmente, as raízes de mudas transplantadas mais novas não tiveram restrição, estabelecendo-se e desenvolvendo-se com mais facilidade. Para as cucurbitáceas, recomenda-se que se transplante as mudas com três semanas (BORNE, 1999), pois são plantas com desenvolvimento rápido. Neste experimento, a melhor idade foi de 19 dias, ou seja, pouco menos de três semanas. Já na cultura de melancia, VAVRINA et al. (1993) relataram que a idade da muda não afetou a produção. Em pepino, SEABRA JúNIOR et al. (2004) observaram redução na produção com a utilização de mudas velhas.

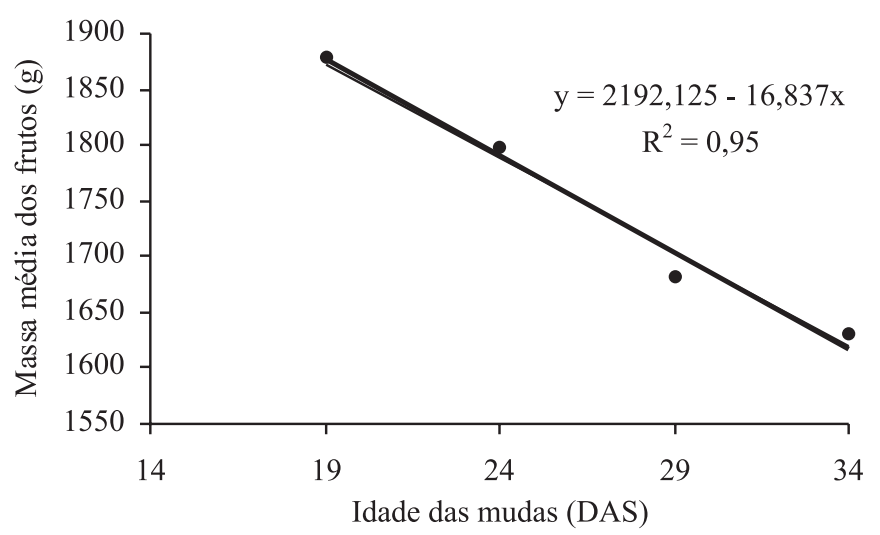

Figura 3. Massa média dos frutos de abóbora em função da idade das mudas (DAS - dias após a semeadura).

Observou-se que quanto maior a idade das mudas, maiores os valores em magnitude de massa fresca e seca e número de folhas, porém, estas mudas mais velhas resultaram em plantas com frutos menores. Assim infere-se que mudas maiores não significam mudas de melhor qualidade. Resultado semelhante também foi observado por SEABRA JúNIOR et al. (2004) em pepino.

No estudo da produção de mudas, a avaliação do desenvolvimento após o transplante é de fundamental importância, visto que nem sempre uma muda avaliada como excelente no momento do transplante é a que vai revelar o maior potencial produtivo, como foi verificado no presente trabalho. Conforme relatado por BELFORT e GOMES (2000), a idade em que as mudas vêm sendo transplantadas pode estar prejudicando sua qualidade, com restrição no sistema radicular e no desenvolvimento após o transplante.

Portanto, mudas mais velhas, com a parte aérea mais desenvolvida e que são as preferidas por alguns produtores por seu sistema radicular compacto e maior facilidade para serem transplantadas, podem reduzir a qualidade de abóbora.

\section{CONCLUSÕES}

1. A diferença no volume de célula da bandeja não influencia a produção e a qualidade dos frutos de abóbora, exceto o comprimento do bojo aos 24 DAS.

2. Quanto maior a idade das mudas, menores o comprimento, o diâmetro e a massa média dos frutos de abóbora.

\section{AGRADECIMENTOS}

À FAPESP, pela concessão de bolsa de iniciação científica à primeira autora (processo 06/ 55535-2).

\section{REFERÊNCIAS}

BARNABÉ, F.A.; GIORGETTI, J.R. Influência de três tipos de bandejas para produção de mudas de berinjela. Horticultura Brasileira, v.18, p.71, 1994.

BARROS, S.B.M. Avaliação de recipientes na produção de mudas de tomate (Lycopersicon esculentum Mill.) e pepino (Cucumis sativus L.). 1997. 70f. Dissertação (Mestrado em Agronomia), Escola Superior de Agricultura "Luiz de Queiroz"-USP, Piracicaba.

BELFORT, C.C.; GOMES, M.S.F.D. Avaliação da idade de transplantio para mudas de melancia. Horticultura Brasileira, v.18, p.468-469, 2000.

BORNE, H.R. Produção de mudas de hortaliças. Guaíba: Agropecuária, 1999. 187p.

ECHER, M.M.; ARANDA, A.N.; BORTOLAZZO, E.D.; BRAGA, J.S.; TESSARIOLI NETO, J. Efeito de três substratos e dois recipientes na produção de mudas de beterraba. Horticultura Brasileira, v.18, p.509-510, 2000.

EMPRESA BRASILEIRA DE PESQUISA AGROPECUÁRIA. Sistema brasileiro de classificação de solos. Brasília: Embrapa, 1999. 412p.

HALL, M.R. Cell size of seedling containers influences early vine growth and yield of transplanted watermelon. HortScience, v.24, 771-773, 1989.

KEMBLE, J.M.; DAVES, R.G.G.; SANDERS, D.C. Spacing, root cell volume, and age effect production and economics of compact-growth-habit tomatoes. HortScience, v.29, p.1460$1464,1994$.

LESKOVAR, D.I.; CANTLIFFE, D.J.; STOFFELLA, P.J. Growth and yield of tomato plants in response to age of transplants. Journal of the American Society for Horticultural Science, v.116, p.416-420, 1991.

LIU, A.; LATIMER, J.G. Root cell volume in the planter flat affects watermelon seedling development and fruit yield. HortScience, v.30, p.242-246, 1995. 
MAYNARD, E.T.; VAVRINA, C.S.; SCOTT, W.D. Containerized muskmelon transplants: cell volume effects on pretransplant development and subsequent yield. HortScience, v.31, p.58-61, 1996.

MINAMI, K. Produção de mudas de alta qualidade em horticultura. São Paulo: T. A. Queiroz, 1995. 138p.

MODOLO, V.A. Avaliação de recipientes e substratos para a produção de mudas de quiabeiro (Abelmoschus esculentus [L.] Moench.). 1998. 53f. Dissertação (Mestrado em Agronomia), Escola Superior de Agricultura "Luiz de Queiroz"-USP, Piracicaba.

NESMITH, D.S. Transplant age influences summer squash growth and yield. HortScience, v.28, p.618-620, 1993.

NESMITH, D.S.; DUVAL, J.R. The effect of container size. HortTechnology, v.8, n.4, p.495-498, 1998.

PEREIRA, P.R.G.; MARTINEZ, H.E.P. Produção de mudas para o cultivo de hortaliças em solo e hidroponia. Informe Agropecuário, v.20, p.24-31, 1999.

RAIJ, B. van; CANTARELLA, H.; QUAGGIO, J.A.; FURLANI, A.M.C. Recomendações de adubação e calagem para o Estado de São Paulo. 2.ed. Campinas: Instituto Agronômico \& Fundação IAC, 1996. 285p. (Boletim Técnico, 100)

SEABRA JÚNIOR, S.; GADUM, J.; CARDOSO, I.I. Produção de pepino em função da idade das mudas produzidas em recipientes com diferentes volumes de substrato. Horticultura Brasileira, v.22, p.610-613, 2004.

SILVA, A.C.R.; FERNANDES, H.S.; MARTINS, S.R.; SILVA, J.B.; SCHIEDEC, G.; ARMAS, E. Produção de mudas de alface com vermicompostos em diferentes tipos de bandeja. Horticultura Brasileira, v.18, p.512-513, 2000.

VAVRINA, C.S.; OLSON, S.; CORNELL, J.A. Watermelon transplant age: influence on fruit yield. HortScience, v.28, p.789-790, 1993. 